\title{
Clinical Study \\ Effects of a New Flavonoid and Myo-Inositol Supplement on Some Biomarkers of Cardiovascular Risk in Postmenopausal Women: A Randomized Trial
}

\author{
Rosario D'Anna, ${ }^{1}$ Angelo Santamaria, ${ }^{1}$ Maria Letizia Cannata, ${ }^{1}$ Maria Lieta Interdonato, ${ }^{1}$ \\ Grazia Maria Giorgianni, ${ }^{2}$ Roberta Granese, ${ }^{1}$ Francesco Corrado, ${ }^{1}$ and Alessandra Bitto ${ }^{3}$ \\ ${ }^{1}$ Department of Pediatric, Gynecological, Microbiological, and Biomedical Sciences, University of Messina, 98125 Messina, Italy \\ ${ }^{2}$ Messina University Hospital, A.O.U. “G. Martino”, 98125 Messina, Italy \\ ${ }^{3}$ Department of Clinical and Experimental Medicine, University of Messina, 98125 Messina, Italy
}

Correspondence should be addressed to Rosario D’Anna; rdanna@unime.it

Received 1 July 2014; Revised 9 August 2014; Accepted 9 August 2014; Published 31 August 2014

Academic Editor: Giuseppina T. Russo

Copyright (C) 2014 Rosario D’Anna et al. This is an open access article distributed under the Creative Commons Attribution License, which permits unrestricted use, distribution, and reproduction in any medium, provided the original work is properly cited.

\begin{abstract}
Background and Aim. Cardiovascular risk is increased in women with menopause and metabolic syndrome. Aim of this study was to test the effect of a new supplement formula, combining cocoa polyphenols, myo-inositol, and soy isoflavones, on some biomarkers of cardiovascular risk in postmenopausal women with metabolic syndrome. Methods and Results. A total of 60 women were enrolled and randomly assigned ( $n=30$ per group) to receive the supplement (NRT: $30 \mathrm{mg}$ of cocoa polyphenols, $80 \mathrm{mg}$ of soy isoflavones, and 2 gr of myo-inositol), or placebo for 6 months. The study protocol included three visits (baseline, 6 , and 12 months) for the evaluation of glucose, triglycerides, and HDL-cholesterol (HDL-C), adiponectin, visfatin, resistin, and bonespecific alkaline phosphatase (bone-ALP). At 6 months, a significant difference between NRT and placebo was found for glucose (96 \pm 7 versus $108 \pm 10 \mathrm{mg} / \mathrm{dL})$, triglycerides $(145 \pm 14$ versus $165 \pm 18 \mathrm{mg} / \mathrm{dL})$, visfatin $(2.8 \pm 0.8$ versus $3.7 \pm 1.1 \mathrm{ng} / \mathrm{mL})$, resistin $(27 \pm 7$ versus $32 \pm 8 \mu \mathrm{g} / \mathrm{L})$, and b-ALP $(19 \pm 7$ versus $15 \pm 5 \mu \mathrm{g} / \mathrm{mL})$. No difference in HDL-C concentrations nor in adiponectin levels between groups was reported at 6 months. Conclusions. The supplement used in this study improves most of the biomarkers linked to metabolic syndrome. This Trial is registered with NCT01400724.
\end{abstract}

\section{Introduction}

Cardiovascular disease (CVD) events remain the leading cause of mortality and are a major cause of morbidity and disability in both genders worldwide [1]. CVDs cover a collection of various heart and vascular diseases, among these hypertension, coronary heart, and cerebrovascular diseases represent major public health problems. It is well known that in postmenopausal CVD risk is increased, since the protective effects exerted by estrogens are missing. It is a matter of fact that following menopause, negative changes in blood pressure, glucose level, and lipid profile are frequent, and characterize the so called "metabolic syndrome", responsible for increased CVD risk [2]. Furthermore, the majority of postmenopausal women experience an undesirable weight gain. CVDs have multiple causes; however, most of the events originate from the complications of atherosclerosis, a pathophysiological process that can be prevented by dietary habit [3]. Evidence from epidemiological studies indicates a positive association between reduction in the incidence of CVD and consumption of plant-based foods such as fruit and vegetables [4]. In addition, the relationship between the amount of polyphenolrich food consumption (fruit and fruit juices, tea, wine, and cocoa) and chronic diseases, supports a protective effect of these compounds upon CVD [5]. The meta-analysis by Desch and colleagues [6] has confirmed the blood pressure-lowering capacity of flavonol-rich cocoa products, in a large set of trials. It has been estimated that a $3 \mathrm{mmHg}$ reduction in systolic blood pressure (SBP) would reduce the relative risk of stroke mortality by $8 \%$, coronary artery disease (CAD) mortality by $5 \%$, and all-cause of mortality by $4 \%$ [7]. Other effects of cocoa-derived products include the improved platelet 
function [8] and the reduction of LDL-cholesterol [4], the major atherogenic lipoprotein.

Besides cocoa flavanols, many other dietary substances have a proven efficacy in reducing CVD risk markers; in previous studies we already shown the protective effects of two naturally occurring molecules, the isoflavone genistein [9] and myo-inositol [10, 11], produced by the human body from glucose. Inositol is a polyol which may be considered a second messenger of insulin [12], and myo-inositol is one of its nine isomers, capable of reducing insulin resistance, blood pressure, and improving lipid profile in a small cohort of postmenopausal women affected by metabolic syndrome [10,11]. The soy-derived isoflavone genistein acting as a natural selective estrogen receptor modulator (SERM) has a proven efficacy on markers of CVD risk [9] and in reducing bone loss in postmenopausal women [13]. Very recently, genistein has shown to reduce insulin resistance, blood pressure, and homocysteine and it improved lipid profile in a cohort of women with metabolic syndrome [14].

In light of these previous experiences and observations, the aim of this study was to test a new supplement formula, combining cocoa polyphenols, myo-inositol, and soy isoflavones, in postmenopausal women with metabolic syndrome. The rationale for this combination therapy is to offer a natural replacement therapy (NRT) that might improve the metabolic conditions in postmenopausal women. In particular, cocoa polyphenols are antioxidants; inositol is an insulin sensitizing agent and soy isoflavones have a positive effect also on bone metabolism.

\section{Subjects and Methods}

2.1. Enrollment and Randomization to Treatments. A 12month, randomized, open-label study was performed. The study protocol was consistent with the principles of the Declaration of Helsinki and has been approved by the Ethics Committee of the University of Messina, Italy. All participants gave written informed consent. Women $(n=60)$ were recruited at the Menopause Outpatients of the University of Messina. Following the criteria for inclusion, women had to be 50 to 60 years old, postmenopausal for at least 12 months at baseline, and diagnosed with metabolic syndrome. Based on the NCEP ATP III [15], the diagnosis of metabolic syndrome in women requires three or more of the five following criteria: (1) waist circumference $\geq 88 \mathrm{~cm}$; (2) triglycerides $\geq 150 \mathrm{mg} / \mathrm{dL}$ or on drug treatment for elevated triglycerides; (3) HDL-C < $50 \mathrm{mg} / \mathrm{dL}$ or on drug treatment for reduced HDL-C; (4) fasting glucose $\geq 100 \mathrm{mg} / \mathrm{dL}$ or on drug treatment for hyperglycemia; (5) blood pressure $\geq 130 / 85 \mathrm{mmHg}$ or on antihypertensive drug. At enrollment a complete family history was obtained and physical examination and routine laboratory evaluation were performed. Almost all the women were hypertensive (55/60) and in treatment with antihypertensive agents.

Exclusion criteria were clinical or laboratory evidence of confounding systemic diseases (e.g., chronic renal or hepatic failure and chronic inflammatory diseases); breast affections or familiar history of breast disease; CVD defined as documented myocardial infarction, ischemic heart disease, coronary heart bypass, coronary angioplasty, cerebral thromboembolism, peripheral amputations, and coagulopathy; use of oral or transdermal estrogen, progestin, androgens, selective estrogen receptor modulators, or other steroids; treatment in the preceding six months with polyunsaturated n-3 fatty acids supplements and nonsteroidal anti-inflammatory drugs (NSAIDs); smoking habit of more than 2 cigarettes daily. Furthermore, subjects were advised to report on occasional use of NSAIDs to the study investigators. Additional exclusion criteria included history of alcohol or drug abuse, being enrolled in another clinical study, proven hypersensitivity to the study drugs, and concomitant major diseases. A computer generated randomization with sequence random permuted blocks was used to minimize differences between groups, due to the limited number of women. Subjects were assigned to the intervention group (NRT: $n=30$ ) or to the placebo group $(n=30)$.

All participants were counseled on a Mediterranean-style diet composed of $25 \%$ to $30 \%$ energy from fat, less than $10 \%$ from saturated fatty acids, $55 \%$ to $60 \%$ from carbohydrates, and $15 \%$ from protein, with a cholesterol intake less than $300 \mathrm{mg} / \mathrm{d}$ and fiber intake of $35 \mathrm{~g} / \mathrm{d}$ or greater. We used this diet to avoid interference with the lipid profile. Diet adherence was evaluated in all participants during each follow-up visit. Soy products or other dietary supplements were prohibited whereas legumes' intake was suggested to be kept constant overtime. At least 150 minutes per week of moderately intense physical activity (walking or cycling) was recommended.

The treatment (herein after NRT) was given for 6 months and it was composed of $30 \mathrm{mg}$ of cocoa polyphenols, $80 \mathrm{mg}$ of soy isoflavones, and 2 grams of myo-inositol. Both NRT and placebo were in powder. In the following 6-month period only diet was recommended to both groups. Women were followed monthly with telephone calls to reinforce the adherence to the intervention.

The study protocol included three visits (baseline, 6, and 12 months) for evaluation of serum glucose, triglycerides, and HDL-C together with some adipokines: adiponectin, visfatin, and resistin; and a marker of bone turnover: bone-ALP.

2.2. Determination of the Study Variables. Primary outcome was the improvement (as a 20\% change from baseline) of at least one of the parameters that characterize metabolic syndrome: blood pressure, waist circumference, HDL-cholesterol, triglycerides, and fasting glucose. Secondary outcome was the improvement of the studied markers as adiponectin, resistin, visfatin, and bone-ALP.

Fasting glucose was measured using routine colorimetric method (normal range $65-110 \mathrm{mg} / \mathrm{dL}$ ). HDL-C and triglycerides were measured by using a routine enzymatic method (SGM Italia, Italy).

Adiponectin, resistin (all from DRG International Inc., Marburg, Germany), bone-specific alkaline phosphatase (IDS, ltd, Fountain Hills, AZ), and visfatin (Ucsn Life Science, Inc., Houston, TX) were measured using enzyme-linked immunosorbent assay kits from serum samples. Adiponectin 
TABLE 1: Demographic and clinical characteristics of the study groups (mean $\pm \mathrm{SD}$ ).

\begin{tabular}{|c|c|c|c|c|c|c|}
\hline & $\begin{array}{c}\text { NRT } n=30 \\
\text { (basal) }\end{array}$ & $\begin{array}{c}\text { Placebo } n=30 \\
\text { (basal) }\end{array}$ & $P$ & $\begin{array}{r}\text { NRT } n=26 \\
(6 \text { months }) \\
\end{array}$ & $\begin{array}{c}\text { Placebo } n=24 \\
(6 \text { months })\end{array}$ & $P$ \\
\hline Age (years) & $56.3 \pm 3.8$ & $55.5 \pm 4.8$ & 0.3 & & & \\
\hline Menopause (months) & $95.1 \pm 61.6$ & $75.6 \pm 57$ & 0.2 & & & \\
\hline BMI $\left(\mathrm{Kg} / \mathrm{m}^{2}\right)$ & $31.9 \pm 3.8$ & $33.6 \pm 3.9$ & 0.1 & $30.7 \pm 3.9$ & $33.3 \pm 3.3$ & 0.2 \\
\hline $\begin{array}{l}\text { Systolic blood pressure } \\
(\mathrm{mmHg})\end{array}$ & $123.6 \pm 12$ & $132.6 \pm 20$ & 0.09 & $124 \pm 9.1$ & $121.6 \pm 9.8$ & 0.3 \\
\hline $\begin{array}{l}\text { Diastolic blood pressure } \\
(\mathrm{mmHg})\end{array}$ & $80 \pm 8$ & $81.5 \pm 11.9$ & 0.3 & $73.6 \pm 11.2$ & $70 \pm 6.3$ & 0.17 \\
\hline $\begin{array}{l}\text { Waist circumference } \\
(\mathrm{cm})\end{array}$ & $98.6 \pm 6.2$ & $100.8 \pm 12.6$ & 0.2 & $98.8 \pm 6$ & $96.3 \pm 6.9$ & 0.17 \\
\hline
\end{tabular}

TABLE 2: Biomarkers evaluation through the study (mean $\pm \mathrm{SD})$.

\begin{tabular}{|c|c|c|c|c|c|c|c|c|}
\hline & & $\begin{array}{l}\text { Glucose } \\
(\mathrm{mg} / \mathrm{dL})\end{array}$ & $\begin{array}{l}\text { HDL-C } \\
(\mathrm{mg} / \mathrm{dL})\end{array}$ & $\begin{array}{l}\text { Triglycerides } \\
(\mathrm{mg} / \mathrm{dL})\end{array}$ & $\begin{array}{c}\text { B-ALP } \\
(\mu \mathrm{g} / \mathrm{mL})\end{array}$ & $\begin{array}{l}\text { Adiponectin } \\
(\mu \mathrm{g} / \mathrm{mL})\end{array}$ & $\begin{array}{l}\text { Visfatin } \\
(\mathrm{ng} / \mathrm{mL})\end{array}$ & $\begin{array}{c}\text { Resistin } \\
(\mu \mathrm{g} / \mathrm{L})\end{array}$ \\
\hline \multirow{3}{*}{ NRT } & Basal & $110 \pm 10$ & $44 \pm 7$ & $177 \pm 19$ & $15 \pm 6$ & $18 \pm 6$ & $3.8 \pm 1$ & $35 \pm 10$ \\
\hline & 6 months & $96 \pm 7^{*}$ & $50 \pm 6$ & $145 \pm 14^{*}$ & $19 \pm 7^{* *}$ & $17 \pm 4$ & $2.8 \pm 0.8^{* * *}$ & $27 \pm 7^{* *}$ \\
\hline & 12 months & $98 \pm 6^{\# \#}$ & $50 \pm 5$ & $156 \pm 15^{\S}$ & $26 \pm 6^{\# \#}$ & $19 \pm 5^{\# \#}$ & $2.9 \pm 1^{\# \#}$ & $26 \pm 8^{\S \S}$ \\
\hline $\begin{array}{l}\text { Basal versus } 6 \\
\text { months }\end{array}$ & $P$ value & $<0.001$ & 0.06 & $<0.001$ & $<0.001$ & 0.48 & 0.002 & 0.0016 \\
\hline \multirow{3}{*}{ Placebo } & Basal & $105 \pm 7$ & $45 \pm 6$ & $180 \pm 20$ & $16 \pm 6$ & $22 \pm 5$ & $4 \pm 1$ & $30 \pm 9$ \\
\hline & 6 months & $108 \pm 10$ & $46 \pm 8$ & $165 \pm 18$ & $15 \pm 5$ & $16 \pm 7$ & $3.7 \pm 1.1$ & $32 \pm 8$ \\
\hline & 12 months & $110 \pm 8$ & $48 \pm 7$ & $176 \pm 22$ & $12 \pm 5$ & $12 \pm 6$ & $4 \pm 0.6$ & $35 \pm 10$ \\
\hline $\begin{array}{l}\text { Basal versus } 6 \\
\text { months }\end{array}$ & $P$ value & 0.23 & 0.62 & 0.008 & 0.53 & 0.0013 & 0.32 & 0.42 \\
\hline
\end{tabular}

${ }^{*} P<0.001$ versus placebo 6 months; $P=0.004$ versus placebo 6 and 12 months; ${ }^{* *} P=0.02$ versus placebo 6 months; ${ }^{* * *} P=0.001$ versus placebo 6 months;

${ }^{\# \#} P<0.001$ versus placebo 12 months; ${ }^{\S} P=0.004$ versus placebo 12 months; ${ }^{\S \S} P=0.009$ versus placebo 12 months.

limit of detection was $0.2 \mu \mathrm{g} / \mathrm{mL}$ with an intra-assay $\mathrm{CV}$ of $7.5 \%$ and an interassay $\mathrm{CV}$ of $6.5 \%$. Resistin limit of detection was $0.012 \mathrm{ng} / \mathrm{mL}$ with an intra-assay $\mathrm{CV}$ of $5.2 \%$ and an interassay CV of $7 \%$. Visfatin limit of detection was $6.3 \mathrm{pg} / \mathrm{mL}$ with an intra-assay CV of $9 \%$ and an interassay CV of $10 \%$. Bone-ALP limit of detection was $0.7 \mu \mathrm{g} / \mathrm{L}$ with an intra-assay $\mathrm{CV}$ of $4.5 \%$ and an interassay CV of $5.8 \%$.

2.3. Adverse Events. Participants were also followed and monitored by their general practitioners (who served as external monitors), who received a detailed synopsis of the trial and were unaware of the treatment arm. At clinical visit every 6 months, women were asked about symptoms. Standard clinical evaluations and routinary laboratory analyses were done every 6 months. All unfavorable and unintended clinical effects were considered adverse events and were evaluated for severity, duration, seriousness, and relation to the study drug and outcome.

2.4. Statistical Analysis. The analysis-of-variance (ANOVA) for repeated measures was performed to analyze treatment effects on groups and time and the unpaired $t$-test was used to compare mean differences in continuous variables intra- and intergroups. A $P$ value of 0.05 or less was considered statistically significant. A post hoc power calculation analysis demonstrated over $95 \%$ power when considering as primary endpoint either glycemia or triglycerides, with an alpha error of 0.05. Statistical analysis was performed by using Statistical Package for Social Science (SPSS Statistics 17.0 Chicago, IL) software.

\section{Results}

At the beginning of the study, the 2 groups were comparable for age, BMI, months from menopause, waist circumferences, and blood pressure (Table 1); and for clinical characteristics: serum glucose, HDL-cholesterol, and triglycerides (Table 2).

At the end of the 6 months treatment period, only 26 in the NRT group and 24 in the placebo group remained in the study (Figure 1). In the following six-month period other dropouts occurred, thus only 22 in the treated group and 21 in the placebo group completed the study. Reasons for withdrawal were abdominal pain ( 3 cases) and throat dryness ( 2 cases) and other reasons were not reported.

At 6 months, a significant difference between NRT and placebo was found for glucose, triglycerides, b-ALP, visfatin, and resistin as reported in Table 2 and Figures 2 and 3. No difference in HDL-C concentrations nor in adiponectin levels between groups was reported at 6 months (Table 2 and Figures 2 and 3). At 12 months, after 6 months from the end of the treatment period, in addition to glucose, triglycerides, 


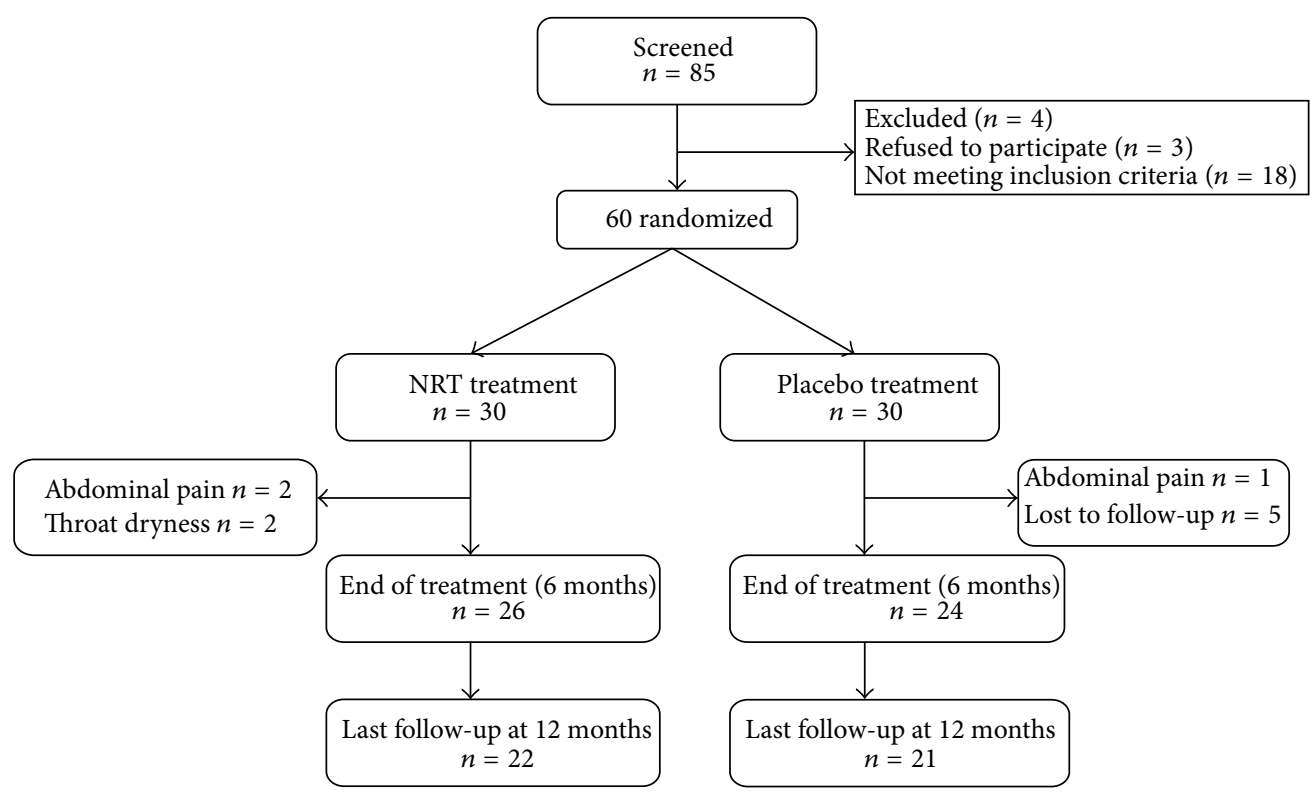

FIGURE 1: Study flow chart.

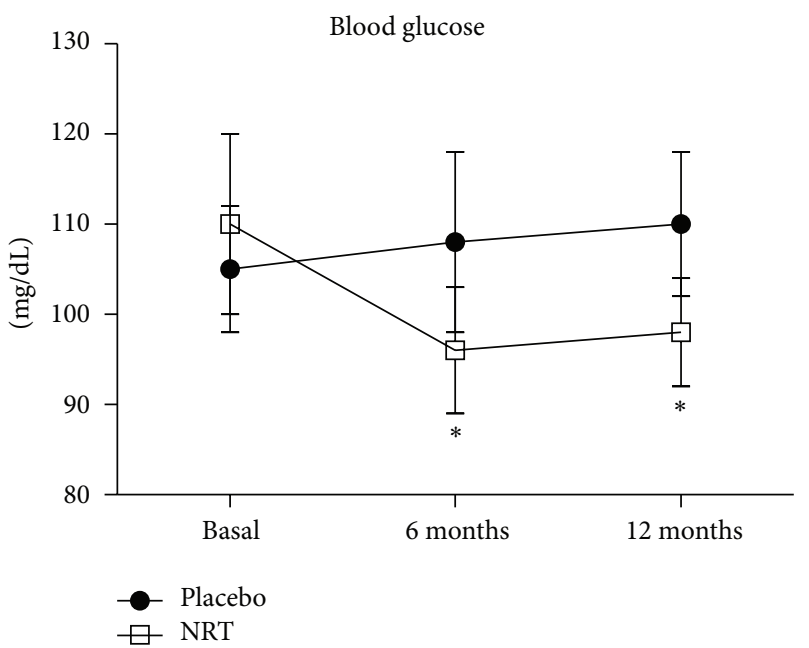

(a)

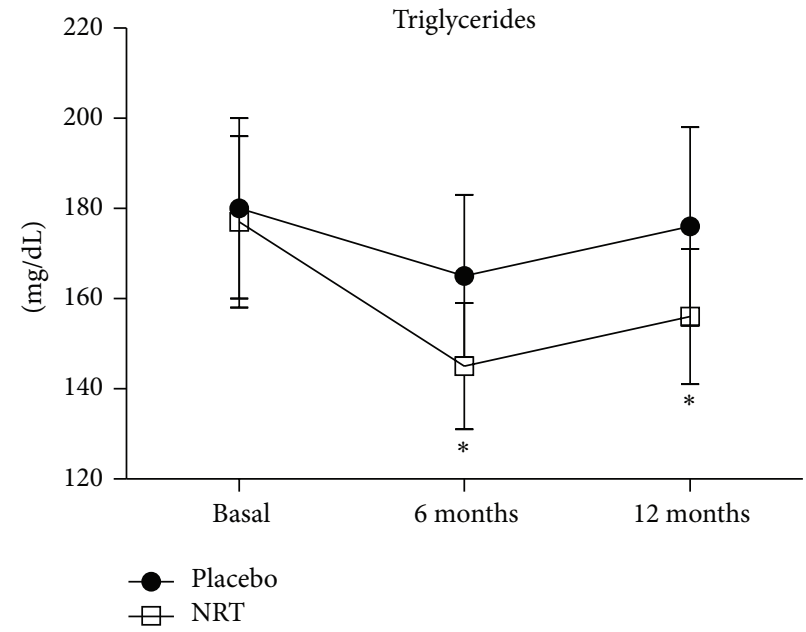

(b)

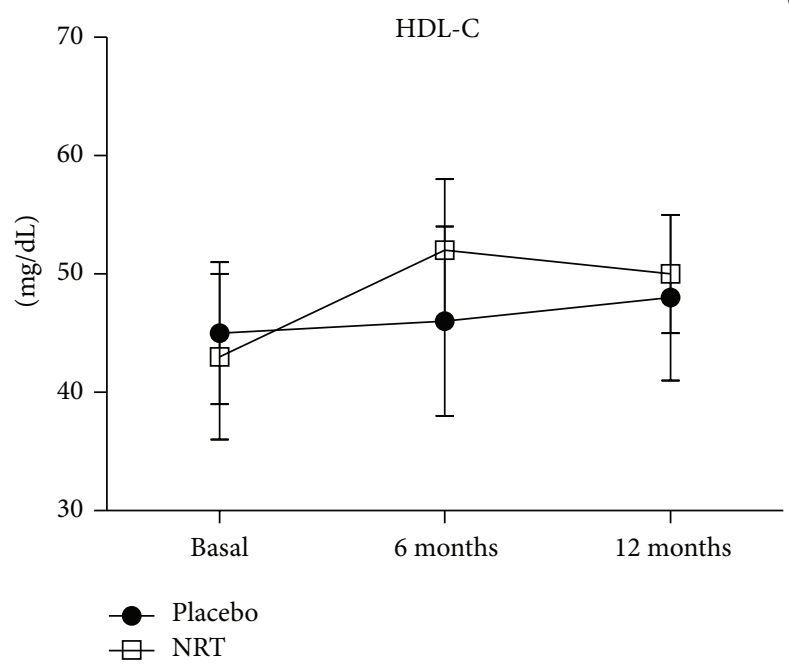

(c)

Figure 2: Glucose, triglycerides and HDL-cholesterol blood levels through the study. ${ }^{*} P<0.05$ versus basal. 


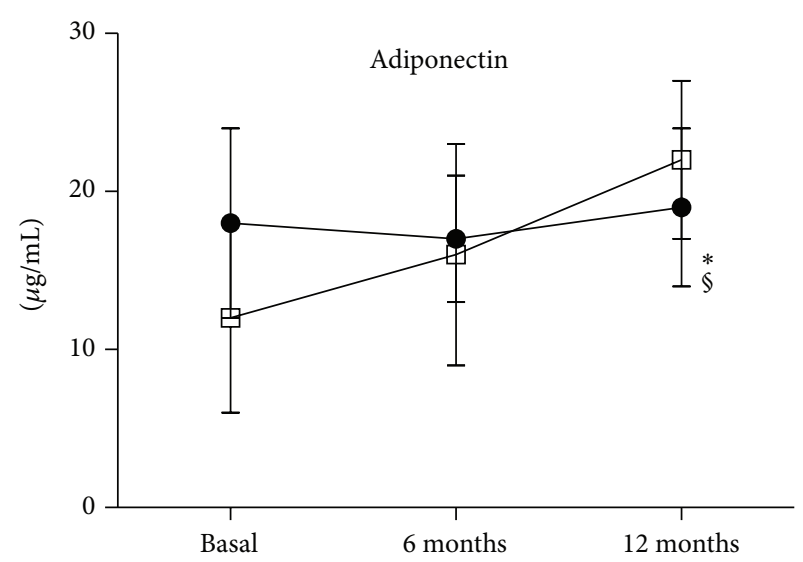

(a)

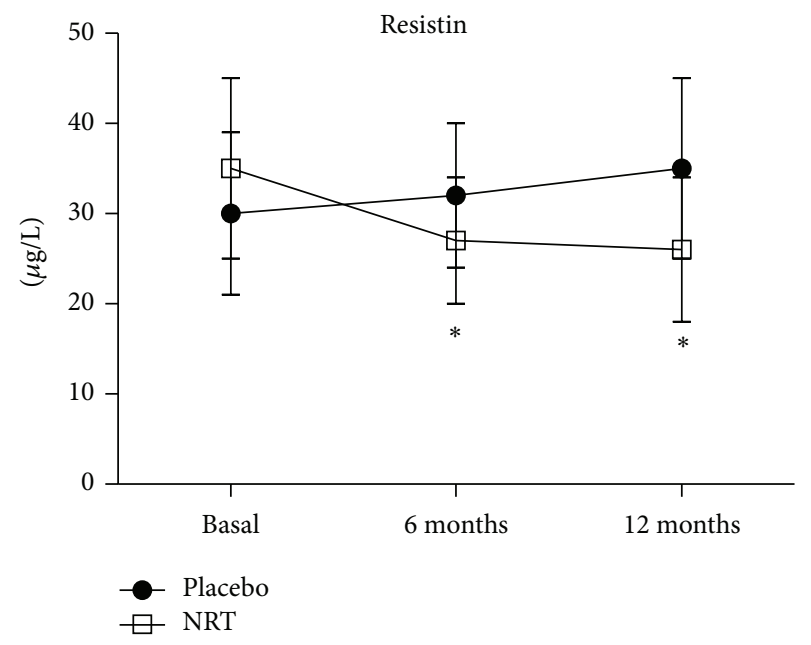

(c)

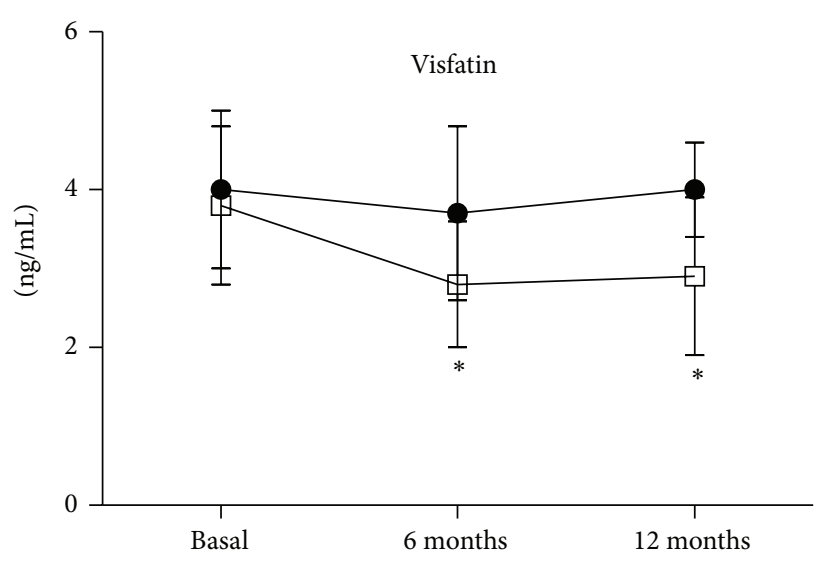

(b)

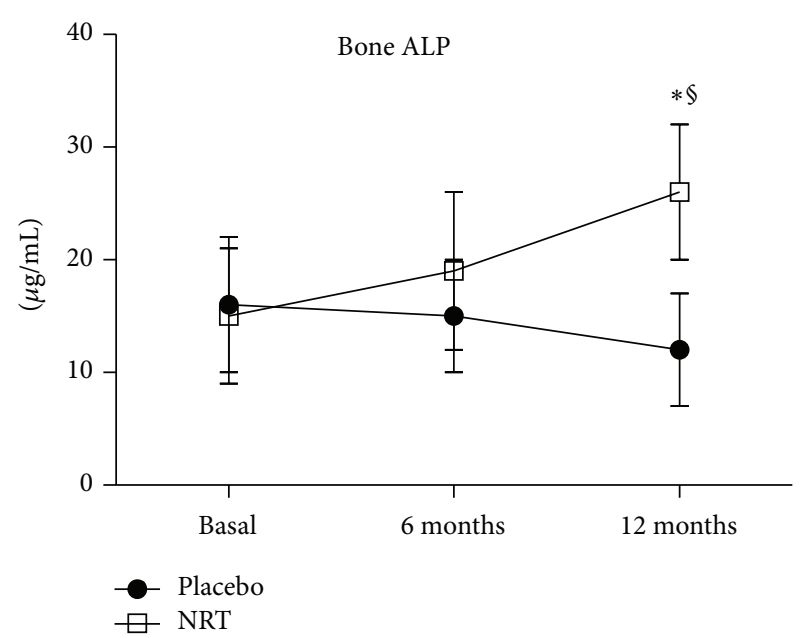

(d)

Figure 3: Adiponectin, visfatin, resistin, and bone-ALP blood levels through the study. ${ }^{*} P<0.05$ versus basal; ${ }^{\S} P<0.05$ versus placebo.

b-ALP, visfatin, and resistin, also adiponectin levels were significantly changed in NRT group, compared to placebo (Table 2 and Figures 2 and 3).

The intra-group analysis revealed that only HDL-C and adiponectin were not affected by NRT treatment at the end of the 6 months, while all the other studied variables were significantly changed from basal values (Table 2 and Figures 2 and 3). In the placebo group after 6 months a significant difference from basal values was observed for triglycerides and adiponectin, probably due to diet, despite no changes in BMI were noted in the enrolled subjects (Table 2 and Figures 2 and 3$)$.

\section{Discussion}

The results of this study demonstrate a protective effect on cardiovascular markers following 6 months administration of a combination of myo-inositol, soy isoflavones, and cocoa polyphenols, in postmenopausal women with metabolic syndrome.
A limit of this study is the number of women enrolled, which reduced the statistical significance of the outcomes; in spite of all that, some interesting results have been obtained. One of these was the persistence, in the six months follow-up period, of the positive results achieved during the six-month treatment period; this data concerns all the markers studied. No differences were highlighted in BMI and waist circumference between and within groups, but this may be due to the short treatment period and somewhat to the low adherence to diet. In the treated group, serum glucose and triglycerides values significantly decreased after six months, maintaining in the subsequent 6 months a significant difference from basal levels. These results are in accordance with other studies, in which each component of the supplement of this trial was used $[10,14,16]$. No difference in HDL-C was shown either between groups or from 6-month to basal values; this data is confirmed by some studies in which only cocoa polyphenols were used $[5,17]$, but not by others $[10,14,16]$, in which a significant difference compared to control group was shown, when each single component of the supplement studied was used. Blood pressure didn't significantly change through the 
study period, although significant differences were highlighted in other studies in which either myo-inositol or cocoa polyphenols were used $[6,10]$; probably the limited number of women studied has negatively influenced this outcome. More interesting were the data about biomarkers which usually depend on insulin resistance. In particular, serum adiponectin levels were significantly increased, after 12 months, in the treated group compared to the control group and also increased at 12 months from basal values in the same group. This result is in accordance with a recent study of our group where genistein aglycone was used [14]. Adiponectin is an adipocyte-specific, secreted protein that sensitizes the liver and muscle to the action of insulin [18]. It is the only adipocyte-derived hormone to be downregulated in the insulin-resistant state, so the levels of adiponectin strongly correlate with basal insulin levels and insulin sensitivity [19]. This explains why low concentrations of adiponectin are associated with increased prevalence of metabolic syndrome, especially in postmenopausal women [20]. If an improvement of insulin resistance is expeceted using isoflavones, because they act through estrogen receptors; or myo-inositol, because of its insulin-like effect [10, 11]; an insulin sensitizing effect is not yet clear for cocoa polyphenols. According to Grassi and coworkers [21], a possible explanation might be found in the positive effect that cocoa extracts have on endotheliumdependent relaxation; in fact, since insulin sensitivity may be in part considered dependent on NO availability, cocoa polyphenols may improve NO production and insulin sensitivity as a consequence [22]. For resistin and visfatin a significant difference occurred only in the treated group, in which both markers were significantly reduced after 6 months of supplement assumption, reaching a plateau until the 12th month. Resistin, is a peptide hormone produced by adipocytes that is more highly expressed in omental and abdominal subcutaneous white fat [23]. In postmenopausal, and in obese women, resistin levels nearly double, representing the hormone that links obesity to diabetes [24]; in addition, a close association of resistin to metabolic syndrome has been recently established [25]. Visfatin role is controversial, but recent evidences have shown increased serum levels in overweight/obese, type- 2 diabetics, metabolic syndrome, and CVD patients [26]. Kim and coworkers [27] have suggested that visfatin may act as the underlying pathophysiological trigger for metabolic syndrome in postmenopausal women and as a marker of abdominal fat deposition and tissue inflammation. The here reported significant reduction in visfatin values, is in agreement with our recent findings in postmenopausal women with metabolic syndrome taking the isoflavone genistein for 12 months [14]. Among the biomarkers evaluated, bone-ALP was also included. This molecule is synthesized by the osteoblasts and it is considered a specific marker of bone formation [28]. In this study, the group receiving the combination formula showed increased levels of bone-ALP over time, with significant differences compared to the placebo group after 12 months and a significant difference with respect to basal values. This result is in accordance with a previous study [29], showing that $54 \mathrm{mg}$ of genistein improved bone turnover, prevented osteoporosis, and increased bone mass density in postmenopausal osteopenic women. Thus, we may hypothesize that probably isoflavones have determined an improvement in bone turnover; however, an experimental study [30] has shown that also myo-inositol is essential for osteogenesis and bone formation.

In conclusion, the supplement used in this study has shown to improve most of the biomarkers linked to metabolic syndrome, suggesting a possible reduction of CVD risk. Furthermore, this study has shown that the positive effects of the supplement may last in the subsequent six months, together with an increase in bone formation. Further studies are warranted to reproduce the present data in a larger cohort of postmenopausal women with metabolic syndrome.

\section{Conflict of Interests}

The authors declare that there is no conflict of interests regarding the publication of this paper.

\section{Acknowledgments}

This work has been supported by departmental funding.

\section{References}

[1] World Health Organization, The Global Burden of Disease: 2004 Update, World Health Organization, Geneva, Switzerland, 2008.

[2] B. Isomaa, P. Almgren, T. Tuomi et al., "Cardiovascular morbidity and mortality associated with the metabolic syndrome," Diabetes Care, vol. 24, no. 4, pp. 683-689, 2001.

[3] T. E. O’Toole, D. J. Conklin, and A. Bhatnagar, "Environmental risk factors for heart disease," Reviews on Environmental Health, vol. 23, no. 3, pp. 167-202, 2008.

[4] L. Dauchet, P. Amouyel, and J. Dallongeville, "Fruit and vegetable consumption and risk of stroke: a meta-analysis of cohort studies," Neurology, vol. 65, no. 8, pp. 1193-1197, 2005.

[5] L. Jia, X. Liu, Y. Y. Bai et al., "Short-term effect of cocoa product consumption on lipid profile: a meta-analysis of randomized controlled trials," The American Journal of Clinical Nutrition, vol. 92, no. 1, pp. 218-225, 2010.

[6] S. Desch, J. Schmidt, D. Kobler et al., "Effect of cocoa products on blood pressure: systematic review and meta-analysis," The American Journal of Hypertension, vol. 23, no. 1, pp. 97-103, 2010.

[7] P. K. Whelton, J. He, L. J. Appel et al., "Primary prevention of hypertension: clinical and public health advisory from the National High Blood Pressure Education Program," Journal of the American Medical Association, vol. 288, no. 15, pp. 1882$1888,2002$.

[8] F. Hermann, L. E. Spieker, F. Ruschitzka et al., "Dark chocolate improves endothelial and platelet function," Heart, vol. 92, no. 1, pp. 119-120, 2006.

[9] M. Atteritano, H. Marini, L. Minutoli et al., "Effects of the phytoestrogen genistein on some predictors of cardiovascular risk in osteopenic, postmenopausal women: a two-year randomized, double-blind, placebo-controlled study," Journal of Clinical Endocrinology and Metabolism, vol. 92, no. 8, pp. 3068-3075, 2007.

[10] D. Giordano, F. Corrado, A. Santamaria et al., "Effects of myoinositol supplementation in postmenopausal women with 
metabolic syndrome: a perspective, randomized, placebocontrolled study," Menopause, vol. 18, no. 1, pp. 102-104, 2011.

[11] A. Santamaria, D. Giordano, F. Corrado et al., "One-year effects of myo-inositol supplementation in postmenopausal women with metabolic syndrome," Climacteric, vol. 15, no. 5, pp. 490495, 2012.

[12] A. R. Saltiel, "Second messengers of insulin action," Diabetes Care, vol. 13, no. 3, pp. 244-256, 1990.

[13] H. Marini, L. Minutoli, F. Polito et al., "Effects of the phytoestrogen genistein on bone metabolism in osteopenic postmenopausal women: a randomized trial," Annals of Internal Medicine, vol. 146, no. 12, pp. 839-847, 2007.

[14] F. Squadrito, H. Marini, A. Bitto et al., "Genistein in the metabolic syndrome: results of a randomized clinical trial," Journal of Clinical Endocrinology and Metabolism, vol. 98, no. 8, pp. 33663374, 2013.

[15] S. M. Grundy, J. I. Cleeman, S. R. Daniels et al., "Diagnosis and management of the metabolic syndrome: an American heart association/national heart, lung, and blood institute scientific statement," Circulation, vol. 112, no. 17, pp. 2735-2752, 2005.

[16] B. Sarriá, S. Martínez-López, J. L. Sierra-Cinos, L. García-Diz, R. Mateos, and L. Bravo, "Regular consumption of a cocoa product improves the cardiometabolic profile in healthy and moderately hypercholesterolaemic adults," The British Journal of Nutrition, vol. 111, no. 1, pp. 122-134, 2014.

[17] L. D. P. Nogueira, M. P. Knibel, M. R. S. G. Torres, J. F. Nogueira Neto, and A. F. Sanjuliani, "Consumption of high-polyphenol dark chocolate improves endothelial function in individuals with stage 1 hypertension and excess body weight," International Journal of Hypertension, vol. 2012, Article ID 147321, 9 pages, 2012.

[18] T. Yamauchi, J. Kamon, H. Waki et al., "The fat-derived hormone adiponectin reverses insulin resistance associated with both lipoatrophy and obesity," Nature Medicine, vol. 7, no. 8, pp. 941-946, 2001.

[19] P. M. Catalano, M. Hoegh, J. Minium et al., "Adiponectin in human pregnancy: implications for regulation of glucose and lipid metabolism," Diabetologia, vol. 49, no. 7, pp. 1677-1685, 2006.

[20] P. Henneman, A. C. J. W. Janssens, M. C. Zillikens et al., "Menopause impacts the relation of plasma adiponectin levels with the metabolic syndrome," Journal of Internal Medicine, vol. 267, no. 4, pp. 402-409, 2010.

[21] D. Grassi, C. Lippi, S. Necozione, G. Desideri, and C. Ferri, "Short-term administration of dark chocolate is followed by a significant increase in insulin sensitivity and a decrease in blood pressure in healthy persons," The American Journal of Clinical Nutrition, vol. 81, no. 3, pp. 611-614, 2005.

[22] M. Karim, K. McCormick, and C. Tissa Kappagoda, "Effects of cocoa extracts on endothelium-dependent relaxation," Journal of Nutrition, vol. 130, no. 8S, supplement, pp. 2105S-2108S, 2000.

[23] C. L. McTernan, P. G. McTernan, A. L. Harte, P. L. Levick, A. H. Barnett, and S. Kumar, "Resistin, central obesity, and type 2 diabetes," The Lancet, vol. 359, no. 9300, pp. 46-47, 2002.

[24] C. M. Steppan, S. T. Bailey, S. Bhat et al., "The hormone resistin links obesity to diabetes," Nature, vol. 409, no. 6818, pp. 307-312, 2001.

[25] E. Malo, O. Ukkola, M. Jokela et al., "Resistin is an indicator of the metabolic syndrome according to five different definitions in the Finnish health 2000 survey," Metabolic Syndrome and Related Disorders, vol. 9, no. 3, pp. 203-210, 2011.
[26] Y. Chang, D. Chang, K. Lin, S. Shin, and Y. Lee, "Visfatin in overweight/obesity, type 2 diabetes mellitus, insulin resistance, metabolic syndrome and cardiovascular diseases: a metaanalysis and systemic review," Diabetes/Metabolism Research and Reviews, vol. 27, no. 6, pp. 515-527, 2011.

[27] J. Kim, S. Kim, J. Im, and D. Lee, "The relationship between visfatin and metabolic syndrome in postmenopausal women," Maturitas, vol. 67, no. 1, pp. 67-71, 2010.

[28] P. D. Ross and W. Knowlton, "Rapid bone loss is associated with increased levels of biochemical markers," Journal of Bone and Mineral Research, vol. 13, no. 2, pp. 297-302, 1998.

[29] H. Marini, A. Bitto, D. Altavilla et al., "Breast safety and efficacy of genistein aglycone for postmenopausal bone loss: a follow-up study," Journal of Clinical Endocrinology and Metabolism, vol. 93, no. 12, pp. 4787-4796, 2008.

[30] Z. Dai, S. K. Chung, D. Miao, K. S. Lau, A. W. H. Chan, and A. W. C. Kung, "Sodium/myo-inositol cotransporter 1 and myoinositol are essential for osteogenesis and bone formation," Journal of Bone and Mineral Research, vol. 26, no. 3, pp. 582590, 2011. 


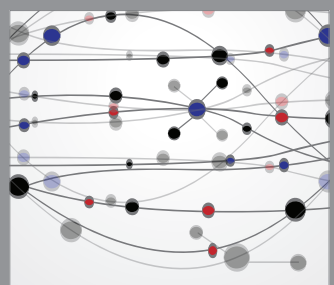

The Scientific World Journal
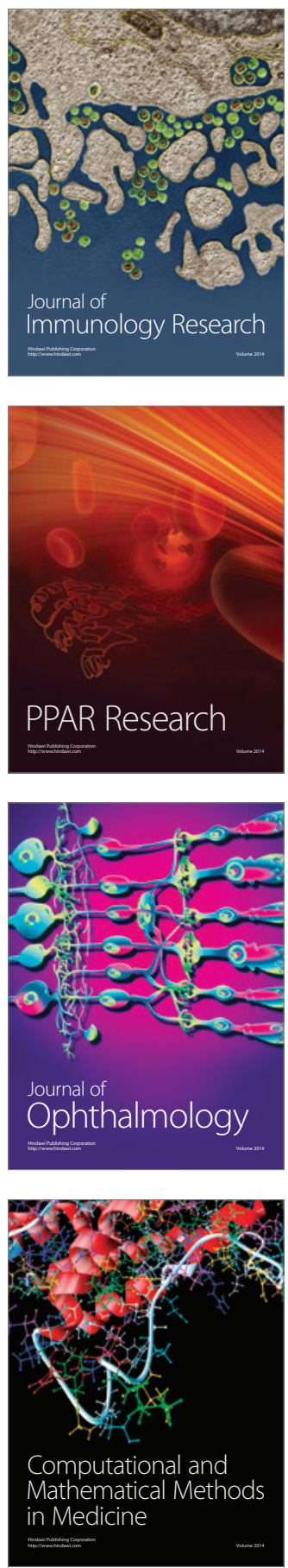

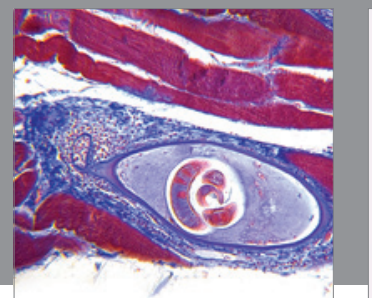

Gastroenterology

Research and Practice
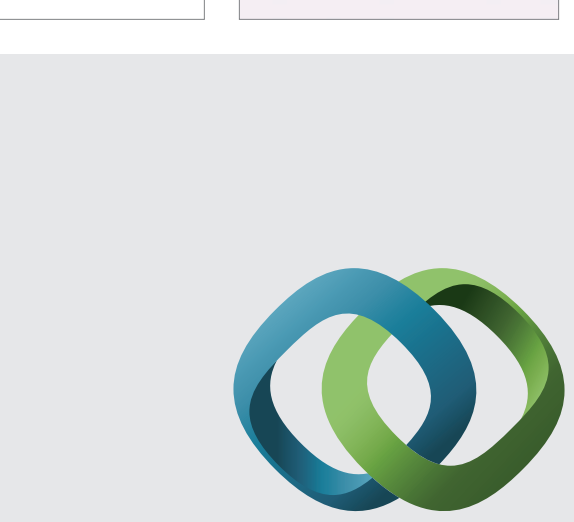

\section{Hindawi}

Submit your manuscripts at

http://www.hindawi.com
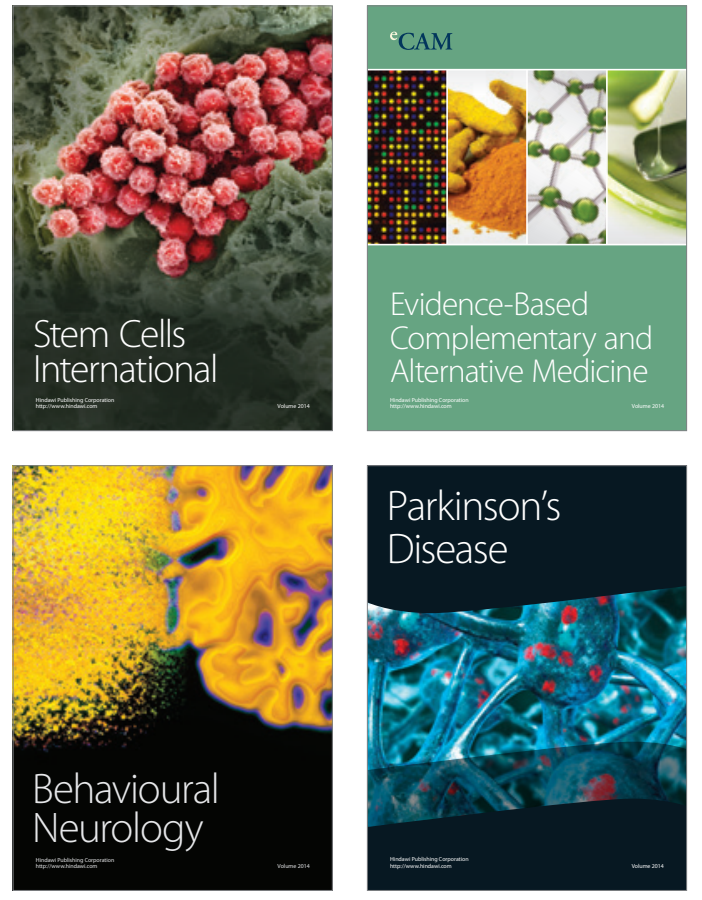
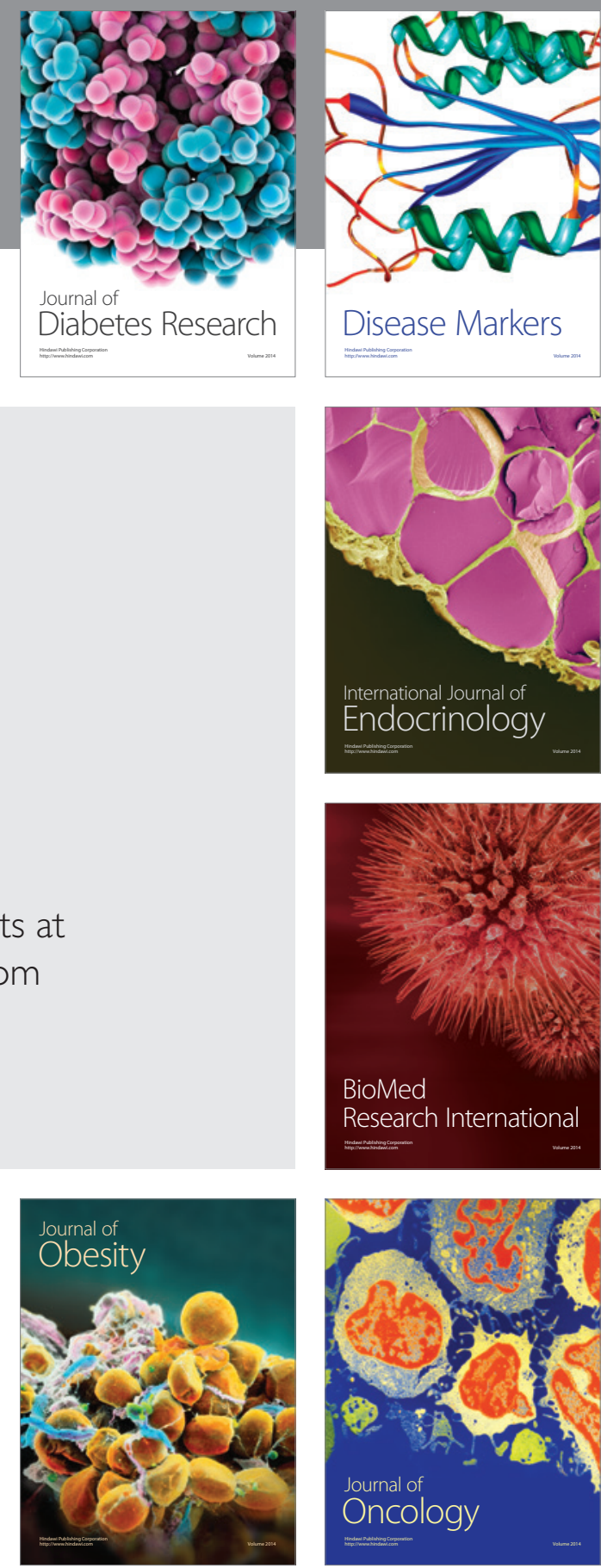

Disease Markers
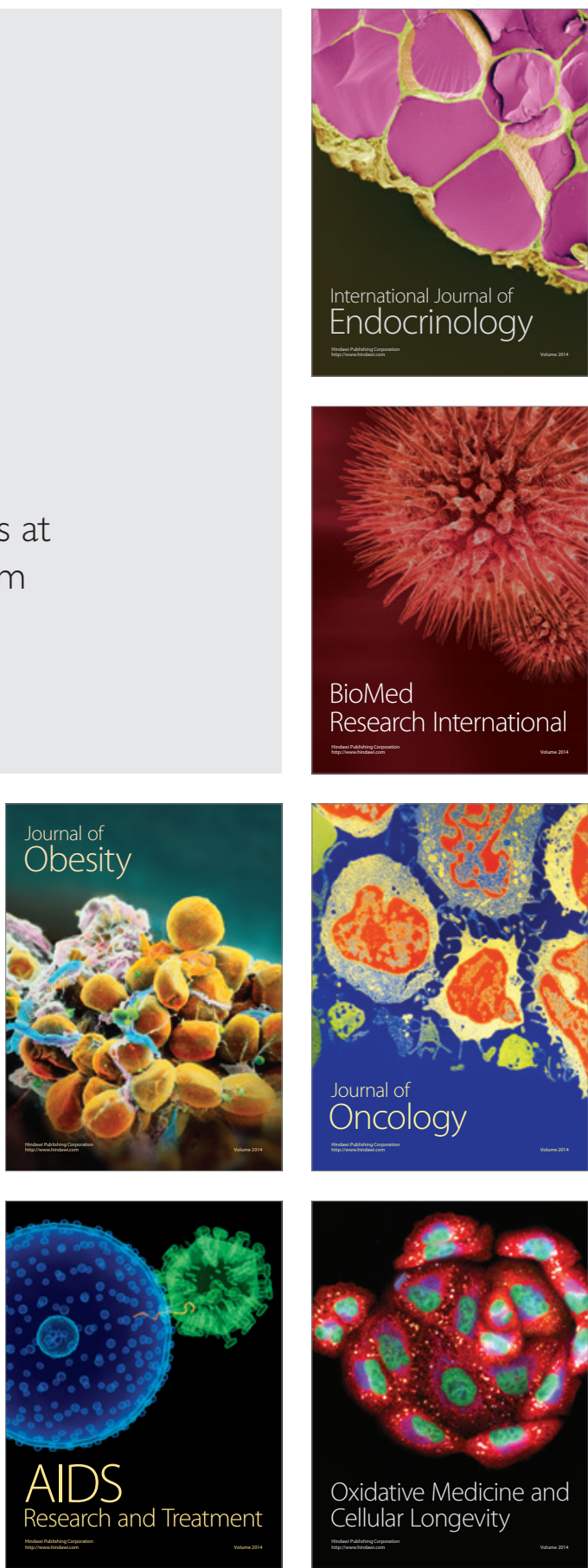